\title{
A monoclonal antibody against a canine CD45 homologue: Analysis of tissue distribution, biochemical properties and in vitro immunological activity
}

\author{
Paulo Henrique Palis Aguiar ${ }^{\mathrm{a}, \mathrm{b}, *}$, Stella Maria Barrouin-Melo ${ }^{\mathrm{a}, \mathrm{b}}$, \\ Carlos Roberto Franke ${ }^{b}$, Roberto Robson Borges dos Santos ${ }^{b}$, \\ Tânia Maria Correia Silva ${ }^{\text {a }}$, José O Mengel ${ }^{a}$, Washington Luis Conrado dos-Santos ${ }^{\text {a,c }}$, \\ Lain Pontes-de-Carvalho a,c \\ ${ }^{a}$ Laboratorio de Patologia e Bio-Intervenção, Centro de Pesquisas Gonçalo Moniz, Fundação Oswaldo Cruz, Bahia, Brazil \\ ${ }^{\mathrm{b}}$ Departamento de Patologia e Clínicas, Escola de Medicina Veterinária Universidade Federal da Bahia, Bahia, Brazil

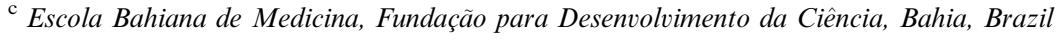

Accepted 2 August 2005

\begin{abstract}
This report describes the characterisation of a monoclonal antibody (mAb), AB6, which recognises specifically a cluster of canine leukocyte surface molecules. The immunogen used for obtaining the AB6 mAb was a lysate of canine peripheral blood mononuclear cells (PBMC). This novel mAb belongs to the IgG2a isotype, and reacted in Western blot with four different canine leukocyte glycoproteins with apparent molecular weights of 180, 190, 205 and $220 \mathrm{kDa}$. The AB6 mAb recognised the majority of canine peripheral blood leukocytes as determined by flow cytometry (97\%). It also exhibited a broad reactivity pattern against lymphoid and myeloid cells, inhibited the proliferation of mitogen-stimulated canine PBMC and did not recognise human PBMC and murine splenocytes. The biochemical properties, cell and tissue specificity, and in vitro biological activity of the AB6 mAb indicate that it recognises a canine CD45 homologue. The mAb could become a valuable diagnostic and research tool for the evaluation of immune functions in dogs.
\end{abstract}

(C) 2005 Elsevier Ltd. All rights reserved.

Keywords: Canine; Leukocyte; Monoclonal antibodies; CD45

\section{Introduction}

The leukocyte-common antigen (L-CA) family, which comprises the CD45 isoforms, is a group of high molecular weight glycoproteins uniquely expressed on the surface of all leukocytes and their haemopoietic progenitors but not other cell types. Members of this family differ in both amino-acid sequence and carbohydrate

\footnotetext{
* Corresponding author. Tel.: +71 356 88781x262; fax: +71 356 4292.

E-mail address: phpa@ufba.br (P.H.P. Aguiar).
}

structures, and are expressed by leukocyte populations in specific patterns (Thomas, 1989). Functionally, the molecules show tyrosine phosphatase activity and are required for normal antigen-induced lymphocyte activation (Trowbridge and Thomas, 1994).

The CD45 molecules show a marked structural heterogeneity with multiple isoforms (ranging from 180 to $220 \mathrm{kDa}$ ) resulting from the alternative splicing of three exons from a common precursor RNA that can generate at least eight different mRNAs (Thomas, 1989).

Two different antigen specificities have been well characterised by biochemical and tissue distribution 
studies (Pulido et al., 1988). One, designated as conventional CD45, is present on all leukocytes and is defined by monoclonal antibodies (mAbs) that recognise epitopes shared by all glycoprotein members of the complex. The second, termed CD45R, is defined in mouse by $\mathrm{mAbs}$ that recognise epitopes found on some but not all isoforms CD45RO (180 kDa), CD45RA (220 kDa) and CD45RB (190, 205 and $220 \mathrm{kDa}$ ) (Sanders et al., 1988; Bottomy et al., 1989; Howard et al., 1991; Bullido et al., 1997).

The different CD45 isoforms show a characteristic pattern of cellular distribution, which is conserved throughout mammalian evolution (Thomas, 1989). B cells express predominantly the largest isoform $(220 \mathrm{kDa})$, thymocytes the smallest $(180 \mathrm{kDa})$, and other $\mathrm{T}$ cells different patterns of isoforms that appear to correlate with their function and prior exposure to antigen: naive $\mathrm{T}$ cells express high molecular weight isoforms, whereas memory $\mathrm{T}$ cells express the lowest molecular weight isoform. The polymorphism of these molecules has also been demonstrated by using mAbs that can detect antigenic differences within the CD45 complex. In man, this family of molecules is composed of as many as five high-molecular weight glycoproteins or isoforms (of 180, 190, 205, 220 and $240 \mathrm{kDa}$ ) present on the surface of the majority of leukocytes. On the other hand, in sheep and cattle, CD45 isoforms of three distinct sizes have been observed, of molecular weights $190,210,225 \mathrm{kDa}$ and $180,205,220 \mathrm{kDa}$, respectively. In the pig, two distinct molecules have been recognised, of 226 and $210 \mathrm{kDa}$ (Zuckermann et al., 1994).

A number of mAbs against canine CD45 molecules have been characterised (Sarmiento and Valli, 1987; Cobbold and Metcalfe, 1994). Nevertheless, as discussed at the First International Canine Leukocyte Antigen Workshop (CLAW), it is difficult to distinguish between antibodies with restricted specificity such as anti-caCD45RB, and those clearly pan-reactive (Cobbold and Metcalfe, 1994). Only one mAb bound to a restrictedly expressed antigen, and showing a weak binding to granulocytes could be designated as anti-canine CD45R (caCD45R). The authors suggested that a further workshop should be convened to establish which mAbs against canine leukocytes would be available and which should still be produced (Cobbold and Metcalfe, 1994). Since then, no other anti-canine CD45 mAb has been described and so, to the best of our knowledge, the $\mathrm{AB} 6 \mathrm{mAb}$ is the most recent reagent with exclusive specificity for canine leukocyte surface molecules of the leukocyte-common antigen family.

In this paper, the generation and characterisation of an anti-caCD45 $\mathrm{mAb}$ are described, according to biochemical, flow cytometric, immunohistochemical and functional analyses. This novel antibody might become a possible valuable diagnostic and research tool to assess canine immune functions.

\section{Materials and methods}

\subsection{Animals and tissues}

All procedures carried out on the animals were in accordance with guidelines defined by the Committee of Ethics in Animal Experimentation of the Oswaldo Cruz Foundation, Bahia, Brazil, and in agreement with the points raised by Higgins (2001).

Two normal 24-36 months old mongrel dogs, weighting about $15 \mathrm{~kg}$ each, were used in the study. The dogs were kept separately, under standard care and feeding conditions, in the kennel of Gonçalo Moniz Research Center, Oswaldo Cruz Foundation and were routinely used as blood donors. Normal dog tissues were obtained from the Department of Pathology and Clinics, Veterinary School, Federal University of Bahia. The specimens were derived from the necropsy of animals that had been euthanased for a variety of reasons.

Ten six-month old, female BALB/c mice, maintained under standard conditions, from the breeding stock of the Gonçalo Moniz Research Center, were used for immunisation with dog antigens and for obtaining tissues for immunohistochemistry. The same cryostat sections of canine tissues used in immunofluorescence tests were also subjected to immunohistochemical assay. Alternatively, tissues were placed in neutral buffered $10 \%$ formalin for $12 \mathrm{~h}$, and embedded in paraffin wax.

The canine PBMC used for lymphoproliferation came from 39 healthy dogs living in a controlled kennel at the Gonçalo Moniz Research Center, Salvador, Brazil.

\subsection{Antigen preparation and monoclonal antibody production}

The procedure for $\mathrm{mAb}$ production has been described elsewhere (Aguiar et al., 2004). Briefly, canine blood leukocytes were used for immunising BALB/c mice, the splenocytes of which were fused with $\mathrm{SPO}_{2}$ myeloma cells (Sp20-Ag14), following standard procedures (Harlow and Lane, 1988). Hybrid cells showing antibody activity against canine leukocytes were screened by ELISA and the antibody-producing cells were subjected to three subsequent rounds of subcloning steps by limiting dilution to obtain stable hybridomas. Culture supernatants were used in subsequent experiments. The $\mathrm{mAb}$ isotype was determined using a mouse $\mathrm{mAb}$ isotyping kit (monoclonal antibody-based mouse Ig isotyping kit - B\&D PharMingen). The assay was performed following the protocol recommended by the manufacturer.

\subsection{Immunoprecipitation analysis and Western blot}

Canine spleen cells $\left(5 \times 10^{6}\right.$ cells $)$ were suspended in $0.15 \mathrm{M}$ phosphate-buffered saline, $\mathrm{pH} 7.2$ (PBS), subjected to 1220 -s sonification bursts (Sonifier 450 
Brandson) and incubated in an $100 \mathrm{mM} \mathrm{NaCl}, 1 \mathrm{mM}$ PMSF water solution, for $1 \mathrm{~h}$ at $4{ }^{\circ} \mathrm{C}$. The insoluble fraction was removed by centrifugation at $500 \mathrm{~g}$ for $30 \mathrm{~min}$.

The $\mathrm{mAb}$ was coupled to protein A-Sepharose beads (Pharmacia). One millilitre volumes of all spleen cell extracts were incubated with $100 \mu \mathrm{L}$ of protein ASepharose beads for $1 \mathrm{~h}$ and the supernatant was then incubated with $100 \mu \mathrm{L}$ of mAb-coated Sepharose beads for $1 \mathrm{~h}$ at $4{ }^{\circ} \mathrm{C}$, with continuous rotation. The beads were washed with PBS containing $0.05 \%$ of Tween 20 (PBS-T20), resuspended with sodium dodecyl sulfate-polyacrylamide gel electrophoresis (SDSPAGE) sample buffer $(62.5 \mathrm{mM}$ Tris- $\mathrm{HCl}, 2 \% \mathrm{w} / \mathrm{v}$ SDS in $10 \% \mathrm{v} / \mathrm{v}$ glycerol/water) and removed by centrifugation. The protein A-Sepharose immunoprecipitated antigens were run in SDS-PAGE under reducing (with 2-mercaptoethanol) and non-reducing (without 2-mercaptoethanol) conditions, as described by Harlow and Lane (1988). Proteins were then electrophoretically transferred to nitrocellulose membrane and incubated with the hybridoma supernatants, diluted 1:2, in PBS-T20 containing 5\% skimmed milk powder (w/v; PBS-T20-milk), followed by successive incubations with peroxidase-conjugated sheep antimouse immunoglobulin polyclonal antibodies (Sigma Chemical Co.) and a mixture of 3,3'-diaminobenzidine (DAB, Sigma) and $\mathrm{H}_{2} \mathrm{O}_{2}$ in PBS. A normal mouse serum dilution containing approximately $25 \mu \mathrm{g}$ of immunoglobulin per of PBS-T20-milk was used as negative control.

\subsection{Indirect immunofluorescence}

Immunofluorescence reactions were carried out on Tween 20-permeabilized or non-permeabilized canine and human peripheral blood mononuclear cells (PBMC). Cryostat sections (6-8 $\mu \mathrm{m}$ in thickness) of normal canine lymph node, spleen, liver, skin and kidney, were also tested by indirect immunofluorescence. The PBMC or tissue sections were air-dried and fixed in alcohol for $5 \mathrm{~min}$ at room temperature (RT). After three washes in PBS, the tissue sections and PBMC were incubated for 30 min at $37^{\circ} \mathrm{C}$ with hybridoma supernatants diluted 1:2 in PBS or PBS-T20-milk. The detergent was used for membrane permeabilization to guarantee the access of the mAb to cytoplasm epitopes. Irrelevant antibody, diluent and normal mouse serum (diluted 1:500) were used as negative controls. The slides were then washed three times in PBS and incubated for $30 \mathrm{~min}$ with fluorescein isothiocyanate (FITC)-conjugated sheep IgG anti-mouse immunoglobulins (Sigma) diluted 1:200 in 1\% Evans Blue in PBS. After washing three times with PBS for $10 \mathrm{~min}$, the slides were mounted with glycerol buffer and examined by ultraviolet (UV) microscopy.

\subsection{Immunohistochemical staining}

Serial 5-8 $\mu \mathrm{m}$ thick sections were placed on poly-L-lysine (Sigma)-coated slides, and allowed to dry at room temperature. The sections were de-waxed in xylene, rehydrated through graded alcohols to distilled water and subjected to a heat-mediated antigen retrieval treatment following the protocol described by Shi and collaborators (2001). Briefly, the slides were placed into a plastic bag filled with $0.01 \mathrm{M}$ sodium citrate buffer, $\mathrm{pH}$ 6.0, and heated in a steamer for $30 \mathrm{~min}$. Once cooled, the heat-treated slides were washed twice for $5 \mathrm{~min}$ each in PBS. Before staining, endogenous peroxidase was inhibited by incubation with $\mathrm{H}_{2} \mathrm{O}_{2}$ and sodium azide in PBS (Shi et al., 2001). Non-specific biding was blocked by pre-incubation of the slides with $10 \%$ normal rabbit serum and bovine serum albumin in PBS. The hybridoma supernatants were then applied onto the slides and left overnight at $4{ }^{\circ} \mathrm{C}$. After two washes of $5 \mathrm{~min}$ with PBS, the slides were incubated with a 1:600 dilution of a biotin-rabbit anti-mouse immunoglobulin conjugate (DAKO) for $45 \mathrm{~min}$ at $37^{\circ} \mathrm{C}$. The sections were then incubated for $30 \mathrm{~min}$ with a 1:500 dilution of a streptavidin-peroxidase conjugate (Pierce). After two washes with PBS, the peroxidase activity was developed with a mixture of $25 \mu^{-1}$ of 3,3-diamine-benzidine (Sigma) and $0.05 \% \mathrm{H}_{2} \mathrm{O}_{2}$ in PBS for $2 \mathrm{~min}$. The slides were then washed in distilled water, counterstained with haematoxylin, gradually dehydrated with alcohols and mounted in Canadian balsam (Riedel de Haen AG). Control sections either lacked primary antibody or it was replaced by an irrelevant isotype-matched $\mathrm{mAb}$.

\subsection{Flow cytometry}

Ten millilitres of blood, collected by venipuncture of the cephalic vein, were incubated at room temperature, for $15 \mathrm{~min}$, with $40 \mathrm{~mL}$ of a haemolytic solution (8.26 g of $\mathrm{NH}_{4} \mathrm{Cl}, 1 \mathrm{~g}$ of $\mathrm{KHCO}_{3}$ and $0.037 \mathrm{~g}$ of $\mathrm{Na}_{4} \mathrm{ED}$ TA per litre of distilled water). The suspension was centrifuged at $700 \mathrm{~g}$ for $1 \mathrm{~min}$ and the supernatant removed. The cells were washed three times with washing solution $\left(0.1 \% \mathrm{NaN}_{3}\right.$ and $5 \% \mathrm{BSA}$ in PBS) and adjusted to the concentration of $2 \times 10^{7} / \mathrm{mL}$. One hundred microlitres of the cell suspension were delivered into wells of 96-well microplate (Nunc), incubated with a 1:2 dilution of the hybridoma supernatant for $20 \mathrm{~min}$ at $4{ }^{\circ} \mathrm{C}$ and washed three times. FITC-conjugated sheep anti-mouse immunoglobulin (Sigma), diluted 1:200 in PBS, were added to the sediment and incubated for $20 \mathrm{~min}$ at $4{ }^{\circ} \mathrm{C}$. The plate was centrifuged and cells were resuspended in $500 \mu \mathrm{L}$ of washing solution prior to analysis in a FACScan flow cytometer (Becton Dickinson). Negative control samples were stained with the secondary antibody only. This procedure, including the buffers for indirect immunofluorescence labelling, was recommended by 
the Canine Leukocyte Antigen Workshop - CLAW (Cobbold and Metcalfe, 1994).

For two-colour analysis, the cells were incubated with mAbs against canine CD4 (rat anti-canine CD4 monoclonal antibody, Serotec), CD8 (rat anti-canine CD8 monoclonal antibody, Serotec), CD45R (rat anti-canine CD45R, clone YKIX 716, a kind gift of Dr. S. Cobbold). Free binding sites were blocked with $5 \%$ heatinactivated normal canine serum.

Biotinylation of the mAbs was carried out using NHS-biotin (Vector Laboratories) according to the protocol suggested by the supplier.

The reactions with the AB6, anti-CD4, anti-CD8 and anti-CD45 mAb were detected using FITC-conjugated sheep anti-rat immunoglobulin. Reactivity with the biotinylated mAbs was detected using B-phycoerythrinconjugated streptavidin (Sigma).

\subsection{Lymphocyte proliferation assays}

Lymphoproliferative assays were carried out according to Kristensen et al. (1982). Briefly, PBMC were isolated from heparinised blood by Ficoll density sedimentation, washed and cultured with RPMI supplemented with $100 \mathrm{IU}^{-1}$ of penicillin, $100 \mu^{-1}$ of streptomycin, $2 \mathrm{mM}$ L-glutamine and $20 \%$ of heat-inactivated fetal bovine serum in flat-bottomed 96-well microtitre plate wells (Nunc) at a concentration of $2 \times 10^{5}$ cells per well. The cells were incubated for three days in a humidified atmosphere at $37{ }^{\circ} \mathrm{C}$ and $5 \% \mathrm{CO}_{2}$, with medium alone, 0.5 and $4 \mu \mathrm{g} / \mathrm{mL}$ of concanavalin $\mathrm{A}$ (Con $\mathrm{A}$ ), in the presence or absence of the mAbs at different concentrations. The concentrations of 0.5 and $4 \mu \mathrm{g} / \mathrm{mL}$ of Con A corresponded to previously determined sub-optimal and optimal concentrations, respectively. Irrelevant, isotype-matched mouse antibodies were used as negative controls. Cells were pulsed during 14-16 h with $1.6 \mu \mathrm{Ci}$ of $\left[{ }^{3} \mathrm{H}\right]$ thymidine (Amersham Life Sciences) and harvested onto glass fibre filters. The degree of $\left[{ }^{3} \mathrm{H}\right]$ thymidine incorporation was determined in a $\mu$-counter. Proliferative responses were expressed as stimulation indices (SI) in relation to unstimulated cells. A SI $\geqslant 2.5$ was considered indicative of a positive cellular response.

\section{Results}

\subsection{Monoclonal antibody isotypes and molecular weights of recognised antigens}

The AB6 was an IgG2a and was recognised in a Western blot using a canine PBMC lysate as antigen and under non-reducing conditions. There were four proteins with apparent molecular weights of 180, 190, 205 and $220 \mathrm{kDa}$ (Fig. 1). The same set of proteins was recognised in spleen-cell lysates (not shown).

\section{Mw Ctrl AB6}
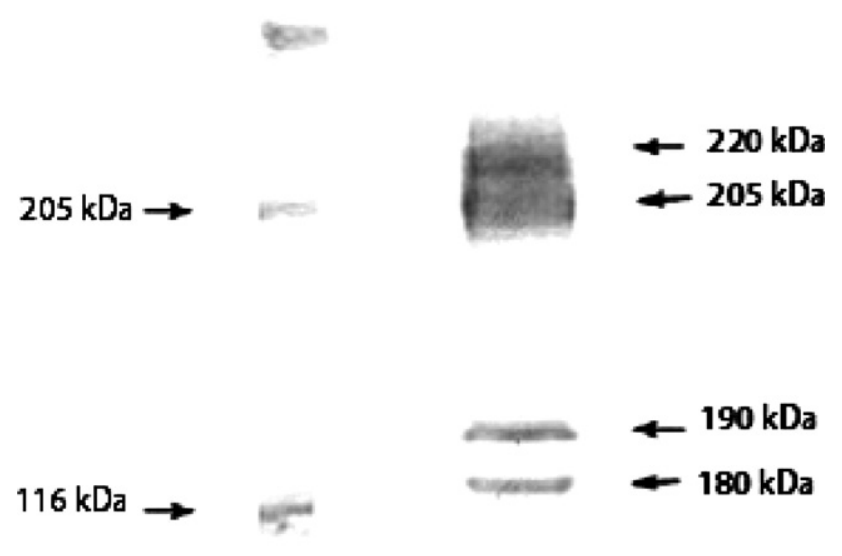

\section{$97.4 \mathrm{kDa} \rightarrow \mathrm{kas}$}

Fig. 1. Western blot of canine PBMC lysates on nitrocellulose membrane, stained with anti-PBMC monoclonal antibody after transferring from non-denaturing $10 \%$ SDS-PAGE. The positions of molecular weight markers are shown on the left. Nitrocellulose strips were incubated with normal mouse serum (negative control - Ctrl) and the AB6 mAb. The positions of estimated molecular weights are shown on the right $(180,190,205$ and $220 \mathrm{kDa})$.

\subsection{Cellltissue specificities of the monoclonal antibody}

Canine cell populations from whole blood were previously identified by size (FSC) and granularity (SSC), using flow cytometric analysis, whose subsets were distinguished in granulocytes, monocytes and lymphocytes. The $\mathrm{mAb}$ recognised most lymphocytes, as shown by flow cytometry (97\% for AB6) (Fig. 2). The antibody did not react with erythrocytes and platelets.

The staining pattern was diffuse and homogeneous, in the presence or absence of membrane permeabilization with Tween 20 . The mAb also stained most mononuclear cells in spleen and lymph node, as shown by immunoperoxidase staining of cryostat sections and immunoperoxidase of paraffin embedded, de-waxed sections (Fig. 3).

Strongly positive cells were found in both the mantle zone and germinal centres of spleen follicles and also in small numbers scattered in the paracortical area. Reticular cells in the red pulp and B cells in the follicular centre were not marked by the mAb. In liver, the AB6 mAb marked only round lymphocyte-like cells, in small inflammatory foci in the parenchyma. In the skin, the AB6 mAb stained cells in inflammatory foci (data not shown). The $\mathrm{mAb}$ stained neither human PBMC nor murine lymph node cells.

Double labelling of canine peripheral leukocytes was performed to confirm their reactivity with either the $\mathrm{CD}^{+}$or $\mathrm{CD}^{+}$subsets of lymphocytes. The $\mathrm{AB} 6$ 

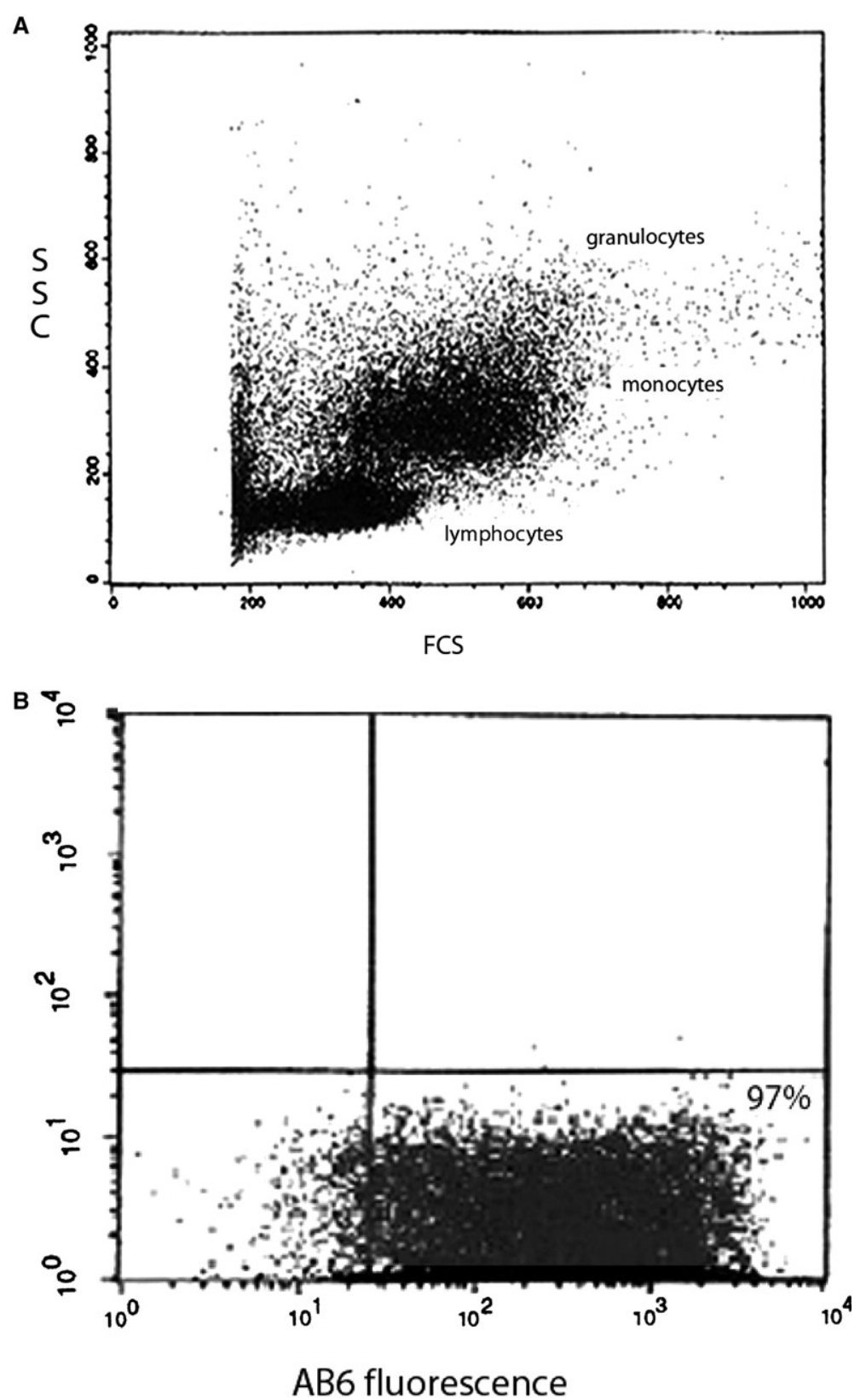

Fig. 2. Flow cytometric analysis of canine whole-blood cells. Light forward-scatter (FSC) and side-scatter (SSC) (A); single staining with the AB6 monoclonal antibody (B).

$\mathrm{mAb}$ reacted with $21.5 \%$ of $\mathrm{CD}^{+}$and $51.0 \%$ of $\mathrm{CD} 8^{+}$ lymphocytes (Fig. 4).

Double labelling with the AB6 mAb and anti-CD45R showed that $63.1 \%$ of the lymphocytes were marked by both antibodies (Fig. 5).

\subsection{Effect of the monoclonal antibodies on the lymphoproliferation of canine PBMC}

To assess the effects of the $\mathrm{mAb}$ on cell proliferation, canine PBMC were incubated with the $\mathrm{mAb}$ or isotypematched IgG2a as negative controls, both in the presence and in the absence of Con A. There was a clear inhibition of the PBMC proliferative response to both optimal and sub-optimal concentrations of Con A when the $\mathrm{mAb}$ was added to the cell culture (Fig. 6). This differed significantly from the percentage of PBMCs with proliferative response inhibited by isotype controls, using the $\mathrm{AB} 6 \mathrm{mAb}(P<0.001$, Wilcoxon's rank sum test).

\section{Discussion}

This paper describes the characterisation of monoclonal antibody raised against non-stimulated canine 

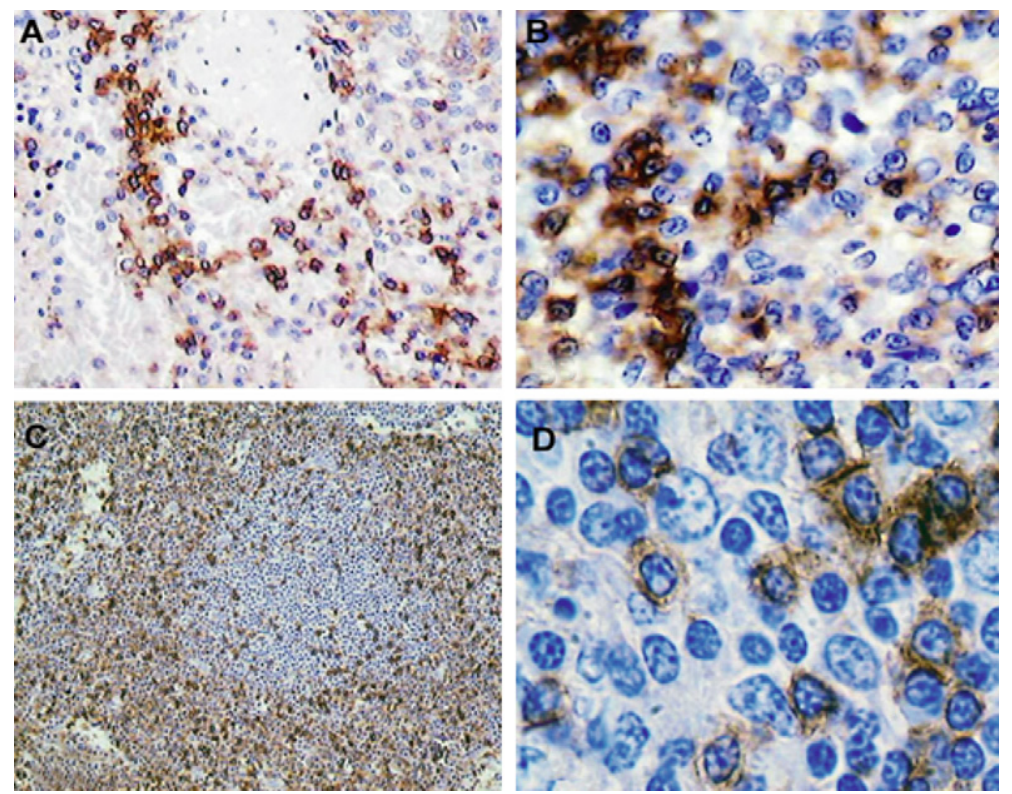

Fig. 3. Immunoperoxidase staining of spleen (A,B) and lymph node (C,D) by the AB6 mAb in formalin-fixed, paraffin-embedded sections. Sections of the spleen show strongly labelled cells scattered in the marginal zone and in the red pulp. In the lymph node, the concentration of stained cells is marked in the mantle zone. Original magnifications: (A) 100×; (B) 200×; (C) 50×; (D) 400×.
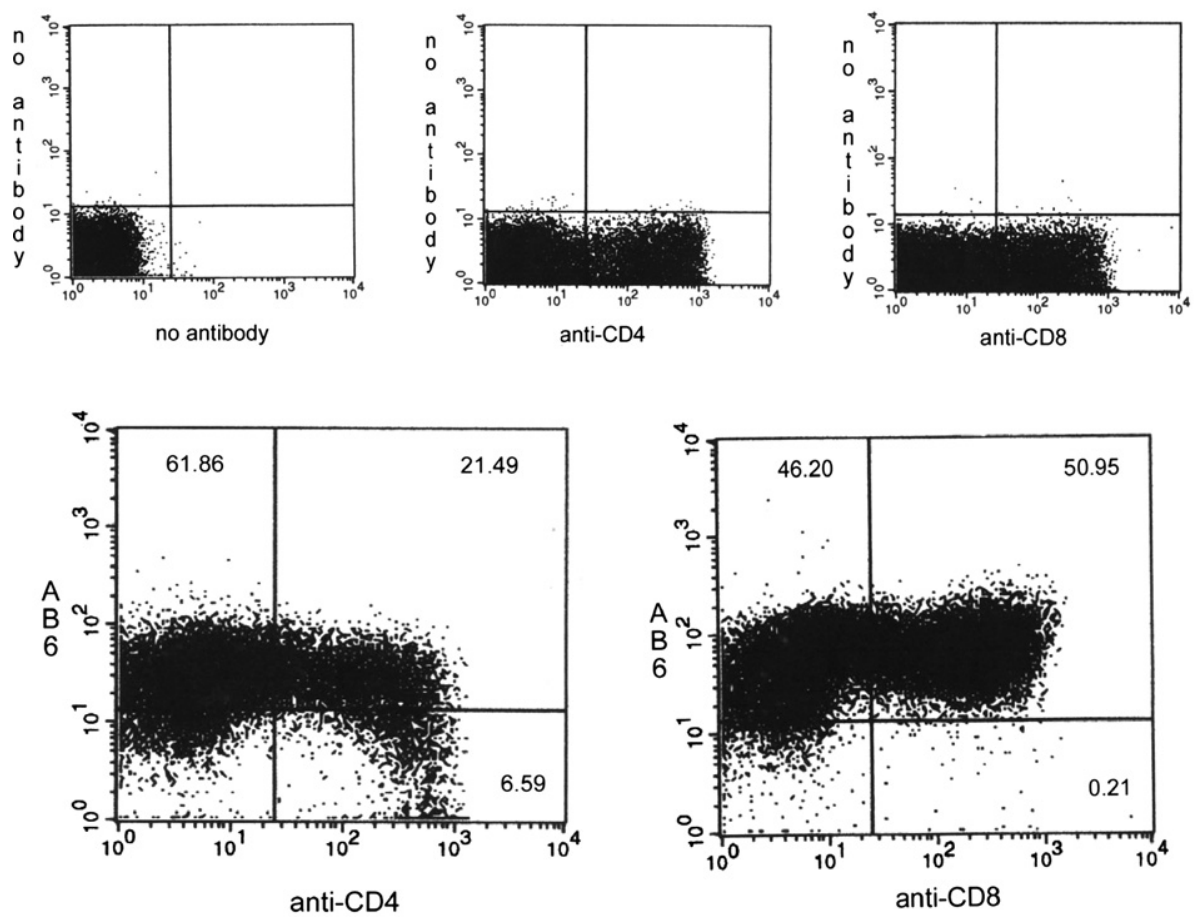

Fig. 4. Two-colour flow cytometric analysis of canine whole-blood cells stained with the AB6 monoclonal antibody and anti-CD4 or anti-CD8 mAbs. Numbers indicate the percentage of cells within the respective regions.

PBMC. Based on functional, histochemical, antigenic specificity and flow cytometric analyses, the AB6 mAb appeared to recognise an analogue of human CD45. Under non-reducing conditions, it identified four different single protein bands, varying from 180 to $220 \mathrm{kDa}$ $(180,190,205$ and $220 \mathrm{kDa})$, similar to other reported
anti-CD45 antibodies to different species, as human $(180,190,205,220$ and $240 \mathrm{kDa})$, bovine $(190,210$ and $225 \mathrm{kDa}$ ), porcine (226 and $210 \mathrm{kDa})$, and murine (180, 190, 205 and $220 \mathrm{kDa})$ (Sanders et al., 1988; Bottomy et al., 1989; Howard et al., 1991; Zuckermann et al., 1994; Bullido et al., 1997). 

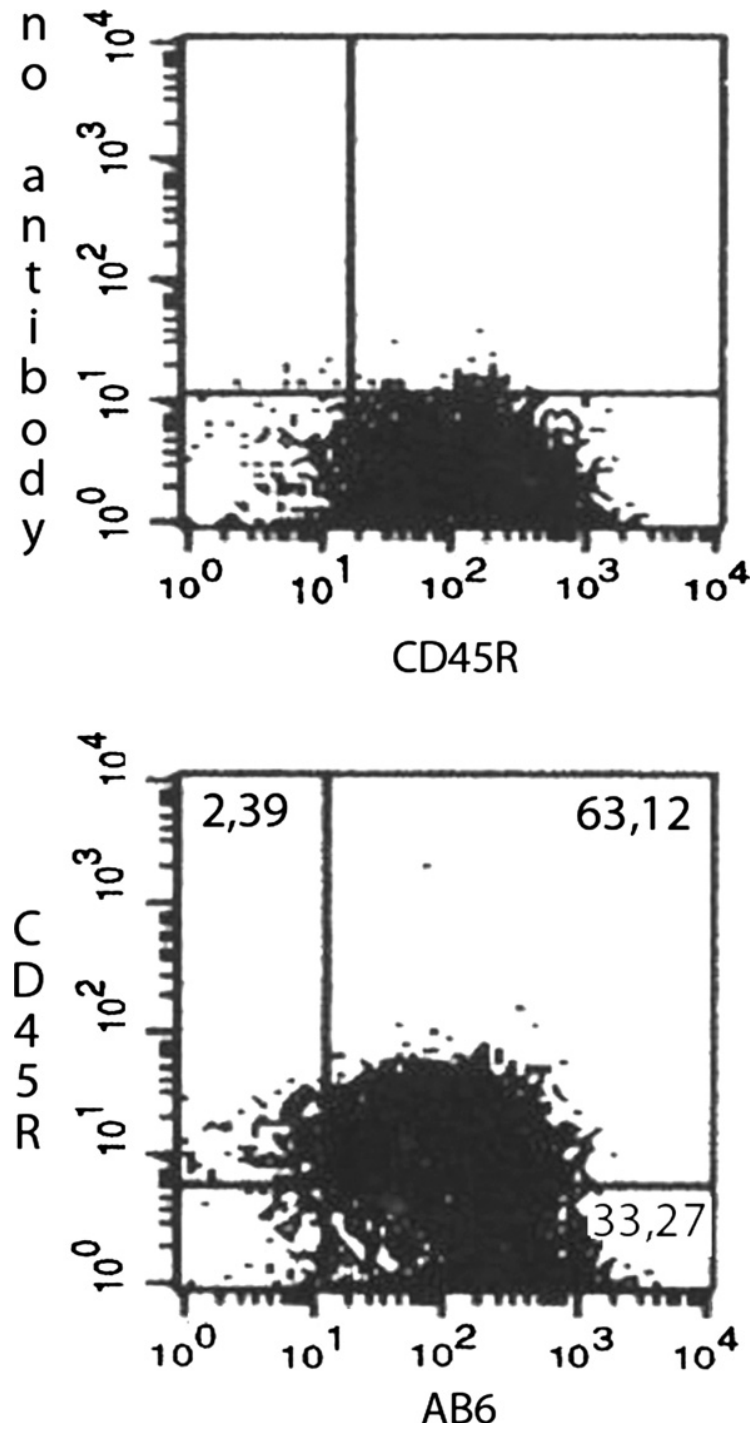

Fig. 5. Two-colour flow cytometric analysis of canine whole-blood cells stained with the AB6 monoclonal antibody and with the antiCD45R. Numbers indicate the percentage of cells within the respective regions.

The $\mathrm{mAb}$ did not react with antigens under reducing conditions, which can be indicative of a property of recognising conformational epitopes. Their binding to live PBMC by flow cytometry demonstrated that they identified membrane proteins, a fact that is again consistent with their recognising CD45 (Thomas, 1989).

The mAb did not identify epitopes on human PBMC and murine lymph node cells. This was also consistent with recognising $\mathrm{CD} 45$, since the interspecies aminoacid sequence homology of the external domains of LCA proteins is as low as 35\% (Thomas, 1989). In fact, only $10 \%$ of cross-reactions were found by Joachin and collaborators (1996) among mAbs against leukocytes from different species such as dogs and cattle.

The staining patterns obtained with the $\mathrm{mAb}$ were similar by both immunohistochemistry and immunofluo-

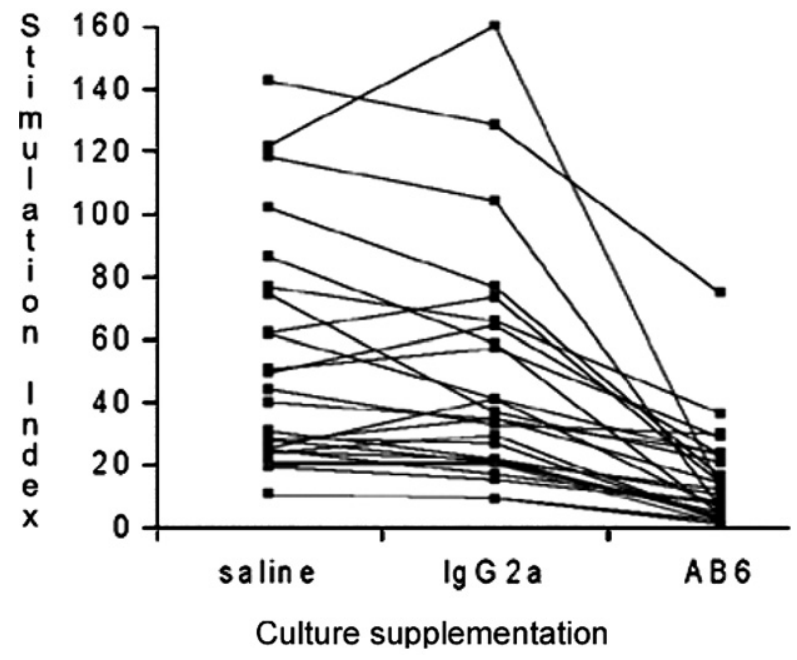

Fig. 6. Inhibition in vitro of the proliferative response of peripheral blood mononuclear cells (PBMCs) to concanavalin A (Con A) by the addition of the AB6 monoclonal antibody from 39 kennel-maintained, healthy animals were incubated with $4 \mu \mathrm{g}$ of Con A per mL and with $20 \mu \mathrm{g} / \mathrm{mL}$ of the AB6 mAb or of an IgG2a isotype control. Each line represents the data obtained from PBMC of an individual dog.

rescence and, in the case of the $\mathrm{AB} 6 \mathrm{mAb}$, on cryopreserved or formalin-fixed paraffin-embedded canine tissue. However, morphological resolution was better when indirect immunoperoxidase technique was performed on formalin-fixed, paraffin embedded sections of tissue.

The AB6 mAb can be a useful tool for the detection of lymphocytes in routinely processed paraffin-embedded tissue sections. It may, therefore, be useful in retrospective studies using routinely processed archived tissues. When the AB6 mAb was tested for possible reaction with human and murine cells by immunofluorescence and immunohistochemistry, no specific recognition was observed.

Many researchers have taken advantage of the crossreactivity that exists between the dog and other animal species' antigens, reporting the use of heterologous antibodies to study canine immunological functions (Galkoswska et al., 1996; Joachin et al., 1996; Williams, 1997; Brodersen et al., 1998; Berndt et al., 2000). Cross-reactivity is not always, however, a reliable way of identifying molecules. Cross-reactive antibodies still require the characterisation of the binding antigen in terms of its molecular weight and distribution on the cells before it can be said that the antibody truly recognises, and only recognises, the canine homologue of the other species' antigen (Williams, 1997).

In flow cytometry analysis, the percentage of lymphocyte stained by the AB6 mAb was $97 \%$ and similar to the percentages are observed with anti-CD45 antibodies in murine, rodent, swine and human lymphocytes (Brodersen et al., 1998; Zuckermann et al., 1994; Faldyna et al., 2001). Also, double staining with 
anti-CD4 and anti-CD8 demonstrated that the mAb recognised lymphocytes of both CD4 and CD8 subsets, and 63.1 of CD45R cell population in double labelling analyses. As the CD45R is an isoform of the CD45 glycoprotein family, whose expression depends on the cell state of differentiation or activation (Zuckermann et al., 1994), it is expected that the percentage of cells carrying it is more restricted, and that the AB6 mAb is quite probably a CD45 pan marker directed towards antigenic determinants encoded by the non-variable exons of the CD45 gene. Its ability to stain all four different protein bands in the Western blot assay is evidence of its broad marking properties.

For studies on the possible effects of the mAb on lymphocyte proliferation, different concentrations of the $\mathrm{mAb}$ were tested on PBMCs stimulated with optimal and sub-optimal concentrations of Con A, a known polyclonal activator of $\mathrm{T}$ cells. With all combinations of $\mathrm{mAb}$ and Con A concentrations, an inhibition of the cell proliferation was observed.

\section{Conclusion}

This is the first report showing the downregulation of canine lymphocyte proliferation by an anti-canine CD45 homologue antibody although such downregulation has been described for murine (Thomas, 1989) and rat cells (Dahlke et al., 2002). As the expression of the different isoforms of CD45 molecules is dependent on cell type, stage of differentiation and activation, their main function is attributable to modulation of the immune response (Zuckermann et al., 1994 and Zuckermann et al., 2001) - a fact that may explain the in vitro inhibition of cell proliferation to mitogen in this study. A possible mechanism could be the induction of cell death by the mAb. T-cell cytolysis in the presence of anti-CD45 has been previously reported for murine cells and associated with the inhibition of CTL function (Thomas, 1989). The mechanisms underlying the inhibition of cell proliferation will be further analysed by more detailed evaluations on the possible occurrence of apoptosis or necrosis on identified leukocyte subpopulations, like $\mathrm{CD}^{+}$and $\mathrm{CD} 8^{+}$cells, under various stimuli in the presence of the AB6 mAb.

A more extensive determination of the properties of the $\mathrm{mAb}$ described in this report requires further studies. The identification of the recognised antigens through their amino acid sequencing are necessary to confirm its anti-CD45 specificity, although the data described here have been considered sufficient to characterise that specificity (Cobbold and Metcalfe, 1994). Based on the properties of exclusive canine species-specific cell recognition, tissue distribution, biochemical characteristics, and biological activity of the AB6 $\mathrm{mAb}$, there may be potential applications for its use in the therapy of immu- nological canine diseases, in the diagnoses of lymphoproliferative disturbances, and in achieving a better understanding of the canine immune response in infection and autoimmunity.

\section{Acknowledgement}

This work was supported by the Brazilian National Council for Research and Technological Development (CNPq).

\section{References}

Aguiar, P.H.P., Santos, R.R.R., Lima, C.A., Gomes, H.R.S., Larangeira, D.F., Santos, P.M., Barrouin-Melo, S.M., dos-Santos, W.L.C., Pontes-de-Carvalho, L., 2004. Production of monoclonal antibodies against canine leukocytes. Hybridomas and Hybridomics 23, 127-132.

Berndt, A., Heller, M., Methner, U., Kosmehl, H., Muller, G., 2000. Monoclonal antibodies against porcine macrophages. Veterinary Immunology Immunopathology 74, 163-177.

Bottomy, K., Lugman, M., Greenbaun, L., Carding, S., West, J., Pasqualini, T., Murphy, D.B., 1989. A monoclonal antibody to murine CD45R distinguishes CD4 $\mathrm{T}$ cell population that produces different cytokines. European Journal of Immunology 19, 617-623.

Brodersen, R., Bijlsma, F., Gori, K., Jensen, K.T., Chen, W., Dominguez, J., Harveson, K., Moore, P., Saalmuller, A., Sachs, D., Slierendrecht, W.J., Stockes, C., Vainio, O., Zuckermann, F., Aaste, B., 1998. Analyses of the immunological cross reactivities of 213 well-characterized monoclonal antibodies with specificities against various leukocyte surface antigens of human and 11 animal species. Veterinary Immunology Immunopathology 64, 1-13.

Bullido, R., Moral, M.G., Doménech, N., Alonso, F., Ezquerra, A., Domínguez, J., 1997. Monoclonal antibodies to a high molecular weight isoform of porcine CD45: biochemical and tissue distribution analyses. Veterinary Immunology and Immunopathology 56, $151-162$.

Cobbold, S., Metcalfe, S., 1994. Monoclonal antibodies that define canine homologues of human CD antigens: summary of the First International Canine Leukocyte Antigen Workshop (CLAW). Tissue Antigens 43, 137-154.

Dahlke, M.H., Lauth, M.D., Jager, D., Roeseler, T., Jacoks, S., Neipp, M., Wonigeit, K., Schlit, H.J., 2002. In vivo depletion of hematopoietic stem cells in the rat by anti-Cd45 (RT7) antibody. Blood 10, 3566-3572.

Faldyna, M., Leva, L., Knotigova, P., Toman, M., 2001. Lymphocyte subset in peripheral blood of dogs - a flow cytometric study. Veterinary Immunology and Immunopathology 82, 23-37.

Galkoswska, H., Waldemar, L.O., Wojewodska, U., 1996. Reactivity of antibodies directed against human antigens with surface markers on canine leukocytes. Veterinary Immunology Immunopathology $53,329-334$.

Harlow, E., Lane, D., 1988. Antibodies: A Laboratory Manual. Cold Spring Harbor Laboratory Press, Cold Spring Harbor, NY.

Higgins, A.J., 2001. Animal research and publications ethics. The Veterinary Journal 162, 81-83.

Howard, C.J., Sopp, P., Parson, K.R., McKeever, D.J., Taracha, E.L., Jones, B.V., MacHugh, N.D., Morrison, W.I., 1991. Distinction of naive and memory BoCD4 lymphocytes in calves with a monoclonal antibody, CC76, to a restrict determination of the bovine leukocyte-common antigen, CD45. European Journal of Immunology 21, 2219-2226. 
Joachin, S.H., Beer, A., Rabe, H.U., Leibold, W., 1996. Reactivity of workshop antibodies with a non-ruminant species: crossreactivity with canine blood leukocytes. Veterinary Immunology and Immunopathology 52, 427-433.

Kristensen, B., Kristensen, F., Vandevelda, M., Higgins, R.J., de Weck, A.L., 1982. Canine lymphocyte cultures in vitro: evaluation of peripheral blood lymphocyte response to mitogens. Veterinary Immunology and Immunopathology 3, 439-448.

Pulido, R., Cebrian, M., Acevedo, A., Landazuri, M.O., SanchezMadrid, F., 1988. Comparative biochemical and tissue distribution study of four distinct CD45 antigen specificities. Journal of Immunology 140, 3851-3857.

Sanders, M.E., Makgoba, M.W., Shaw, S., 1988. Human näve and memory T cells: reinterpretation of helper-inducer and suppressorinducer subsets. Immunology Today 9, 195-199.

Sarmiento, U.M., Valli, V.E., 1987. A canine lymphocyte surface antigen detectable by a monoclonal antibody (DT200). Canadian Journal of Veterinary Research 51, 110-116.
Shi, S.R., Cote, R.T., Taylor, C.R., 2001. Antigen retrieval techniques: current perspectives. Journal Histochemistry Cytochemistry 49, 931-937.

Thomas, M.L., 1989. The leukocyte common antigen family. Annual Review of Immunology 7, 339-369.

Trowbridge, I.S., Thomas, M.L., 1994. CD45: an emerging role as a protein tyrosine phosphatase required for lymphocyte activation and development. Annual Review of Immunology 12, 85-116.

Williams, D.L., 1997. Studies of canine leucocyte antigens: a significant advance in canine immunology. The Veterinary Journal 153, 31-39.

Zuckermann, F.A., Binns, R.M., Husmann, R., et al., 1994. Analyses of monoclonal antibodies reactive with porcine CD44 and CD45. Veterinary Immunology and Immunopathology 43, 293-305.

Zuckermann, F.A., Schnitzlein, W.M., Thacker, E., et al., 2001 Characterization of monoclonal antibodies assigned to the CD45 subgroup of the Third International Swine CD Workshop. Veterinary Immunology Immunopathology 80, 165-174. 